\title{
Arbor
}

\section{La aportación del directivo hospitalario. Análisis de una controversia}

Ricardo Herranz Quintana

Arbor CLXX, 670 (Octubre 2001), 413-422 pp.

El presente artículo esboza una serie de reflexiones sobre la realidad de la práctica directiva en los hospitales del Sistema Nacional de Salud, traspasando los planteamientos teóricos y meditando sobre el sentido del quehacer directivo diario.

Buscaré, expresamente, alejarme del entramado teórico conceptual, sobradamente estudiado en múltiples textos que todos conocemos, para, explorando el «día a día», comentar otros temas, tal vez menos «teorizados» pero siempre presentes en nuestra actividad como directivos.

No siendo habitual que a los directivos se nos convoque a escribir sobre «nosotros mismos», he decidido utilizar un tono irónico, pretendiendo una lejanía imposible de conseguir, pero que se suele decir recomendable a la hora de perseguir la necesaria objetividad con que tratar estos asuntos.

\section{Introducción: marco general}

Formamos parte de una Administración Sanitaria prestadora de servicios que pretendemos de calidad, así hablamos de CALIDAD TO- 
TAL, calidad del PRODUCTO HOSPITALARIO considerado en su conjunto y no como calidad en uno o varios de los elementos que lo integran. Entiendo que el Hospital ofrece un servicio sanitario, integrado por múltiples componentes, sanitarios, hosteleros, informativos, etc., analizables por separado, pero necesariamente integrados a la hora de valorar el servicio que nuestras Instituciones prestan a sus usuarios.

Administración, además, regida por principios de eficiencia en la asignación de recursos. Pretendemos prestar unos servicios suficientes en cantidad y adecuados en calidad, pero que no se pueden producir de cualquier manera, ni a cualquier precio. Los recursos no son ilimitados y cuando los empleamos en la cobertura de determinadas necesidades, necesariamente deberemos dejar otras sin atender, lo que nos obliga al máximo rigor en su gestión.

La Administración habrá de ser, también, transparente en la gestión. La toma de decisiones sobre la asignación de recursos públicos, obliga a tomar en consideración unos principios básicos, establecidos legalmente y que garantizan la transparencia y objetividad con que debemos operar en todo momento.

Necesitamos una Administración competente. Lógicamente, las personas encargadas de la gestión de los recursos públicos, deben contar con. la competencia personal y las competencias profesionales necesarias para que su labor pueda alcanzar el buen fin que todos deseamos.

¿Cuál, en estas circunstancias, es el papel de la FUNCIÓN DIRECTIVA en las organizaciones sanitarias?

\section{Consideraciones iniciales-preguntas insolentes}

¿Por qué las encuestas de clima social, realizadas entre los empleados de los centros sanitarios, suelen revelar una razonable, cuando no intensa, identificación con la Institución, a la par que una escasa o nula identificación con la Dirección?

¿Es la Dirección, entonces, un INTRUSO, un ESTORBO, un ADVENEDIZO, indeseado por la mayoría de los elementos de la organización? En el mejor de los casos, ¿UN MAL NECESARIO?

¿Tiene la Dirección, quienes desempeñan los puestos directivos, alguna idea sobre cómo es considerada y/o percibida por quienes la promueven y por quienes la «soportan»? ¿Tenemos claro POR QUE y PARA QUE estamos aquí?

¿Que relación tiene la Dirección con la oficina del conseguidor? ¿Existe una correcta relación entre lo que se espera de un directivo y los medios de que dispone para conseguirlo? 
¿Tiene todo lo anterior algo que ver con la enorme inestabilidad laboral existente en el colectivo de directivos hospitalarios?

A lo largo del presente trabajo, pretendo sentar unas bases conceptuales mínimas, que permitan aportar contestaciones constructivas $\mathrm{y}$ de futuro a estas preguntas tan insolentes y malintencionadas.

\section{La dirección en la organización}

La Dirección es uno de los elementos más INESTABLES, desde el punto de vista de su consolidación dentro del hospital, de la organización hospitalaria, lo que hace presuponer, de alguna manera, su precaria identificación con la organización (con el hospital) y su más probable identificación con la instancia política de donde procede su designación. ¿Es eso realmente así?

En este caso, ¿Sería cierto que una de las primeras tareas de la Dirección suele consistir en tratar de convencer al resto de la organización de que se identifica con ella, que la respeta, que reúne algún que otro mérito profesional, de competencia y de conocimiento, además del de haber conseguido un nombramiento?.

¿Tendría, entonces, la Función Directiva un contenido con trascendencia propia, separable del poder ejecutivo por una parte y de la idea de representación de colectivos fuertemente organizados por otra?

En cualquier caso, si pudiera pensarse que la fidelización del directivo se obtiene a través del modo de designación para el desempeño del puesto y que éste se produce desde una instancia externa a la organización, no resultaría sorprendente que, entre quienes, con razón o sin ella, se consideran parte integrante de dicha organización, toda Dirección sea vista con recelo, como algo externo, más allá de la natural reticencia de todo ser humano de bien a «ser dirigido y controlado» en su actividad laboral.

En este sentido, dotar a las organizaciones hospitalarias de un órgano de gobierno de carácter estable, plural y razonablemente permanente en su composición, con competencias en la provisión de los puestos de dirección y ante el que esta deba de rendir cuentas, ifacilitaría, en la medida en que la organización lo viva como algo propio, la integración de los equipos de dirección en el entramado hospitalario?

El Real Decreto 29/2.000, sobre Nuevas Formas de Gestión del INSALUD, instaura diversos organismos de gobierno para las cuatro formas reconocidas:

Fundaciones según Ley 30/94: Patronato Sociedades Estatales: Consejo de Administraci in 


\section{Ricardo Herranz Quintana}

Consorcios: Consejo de Gobierno

Fundaciones Públicas Sanitarias: Consejo de Gobierno

En el mismo sentido, el Reglamento de Organización y Funcionamiento del Hospital General Universitario «Gregorio Marañón», aprobado por el Decreto 98 de 4 de Junio de 1.998, recoge, en sus artículos 8, 1112 y 13, la creación de un Consejo de Administración, con competencias en el nombramiento del Equipo Directivo, determinación de las líneas estratégicas de la Institución y exigencia de cuentas sobre su gestión.

\section{El entorno real de la función directiva}

¿Cuál es el entorno relevante de la Función directiva?

¿Quién es su cliente?

- ¿El político? Es quien le nombra y le puede cesar.

- ¿El sindical? Interfiere continuamente, muchas veces incluso en cumplimiento de diversos preceptos legislativos, en la labor de dirección. Influye, de modo sensible, en la instancia política.

- ¿Los destinatarios del servicio que se presta? ¿ Los usuarios? Son el centro y objetivo último de la actividad profesional directiva.

- ¿El resto de la organización? Cada estamento se presenta con su particular inventario de intereses, que el directivo tratará de compatibilizar con los de la Organización.

- ¿Todos los anteriores a la vez? Ciertamente. Todos ellos, en mayor o menor medida, intervienen y condicionan la actividad directiva, hasta el punto de que, en ocasiones, el directivo se asemeja a una barca a la deriva, sometida a las corrientes y demás circunstancias meteorológicas, que la zarandean e impiden discurrir por su rumbo adecuado.

En este contexto, no sería ocioso preguntarnos ¿UNA FUNCIÓN DIRECTIVA O VARIAS FUNCIONES DIRECTIVAS?

¿Es única la Función Directiva en los centros hospitalarios o, por el contrario, existen al menos dos funciones directivas distintas, la que se proyecta sobre la actividad asistencial y la que se proyecta sobre la gestión de los recursos (la de Atención Sanitaria y la de Gestión y Servicios Generales, en el lenguaje habitual)? 
Si fueran dos, ¿tienen o pueden tener intereses contrapuestos, de cuya armonización dependa el direccionamiento de las energías en pos del verdadero interés de la organización? ¿Es cierto que sus diferentes orígenes, tradición, experiencia directiva, relación con la organización y niveles de profesionalización, e incluso de implicación directiva, pueden condicionar esta eventual divergencia de intereses?

En ese caso, correspondería a las Gerencias la mencionada armonización de intereses parciales, en la dirección del interés común de la Organización.

Si llegáramos, por el contrario, a la conclusión de que la función directiva es única, lo que resulta coherente con la existencia de una única organización, que presta un servicio único (asistencia sanitaria hospitalaria, en sus diversas variantes y modalidades), tal como he propuesto anteriormente, que pretende de calidad, será importante que los propios equipos directivos sean conscientes de dicha unidad de acción, asumiéndola bajo cualquier circunstancia y con todas sus consecuencias.

\section{COROLARIO-DEFINICION DE FUNCION DIRECTIVA}

En función de todo lo anteriormente expuesto, podríamos arriesgarnos a proponer una definición de Función Directiva:

«La Función Directiva en el ámbito hospitalario, se establece en unas organizaciones concebidas por $-y$ en buena medida "para»- los profesionales que las componen, como un instrumento de los poderes públicos -financiadores- necesario para racionalizar la gestión de los recursos públicos y reconducir la actividad asistencial-sanitaria hacia los fines establecidos por los órganos competentes, armonizando, para ello, las potencialidades profesionales disponibles, procurando, al mismo tiempo, la máxima satisfacción de los intereses propios de los diversos agentes intervinientes».

La Función Directiva consistiría, entonces, en gestionar unos recursos, a través de una Organización, para proporcionar la satisfacción de los intereses de ciudadanos-pacientes, politicos-planificadores y profesionales-sindicatos.

En este punto, considero relevante dedicar unas líneas a analizar, por su indudable repercusión en el desarrollo de la Función Directiva, a los que se podrían denominar CONDICIONANTES SOCIO-ECONOMICOS.

A) La propia naturaleza del servicio que se presta, favorece la superposición y, en ocasiones, la suplantación de intereses entre profesionales, organización y ciudadanos, por la identificación de los in- 


\section{Ricardo Herranz Quintana}

tereses de los profesionales con los de los ciudadanos y por lo tanto con los de la organización.

Se trata de dos falacias que condicionan fuertemente la Función Directiva:

No asumir ciertos intereses de determinados grupos profesionales, se pretende confundir, en ocasiones, con atentar contra los intereses de la organización y, en última instancia, contra los de los ciudadanos.

Del mismo modo, con cierta frecuencia se considera natural que los intereses de los ciudadanos estén representados, precisamente, por aquéllos a quienes ni los ciudadanos pueden, ni precisan elegir, como son los profesionales, organizaciones corporativas, centrales sindicales, etc y hasta se hace muy raro pensar que los verdaderos representantes de la ciudadanía y de sus intereses, según las reglas del sistema democrático sean, precisamente, los responsables políticos, cuya legitimación para decidir sobre las políticas sanitarias, debe -coherentemente- estar fuera de toda duda, así como su capacidad para designar los equipos directivos adecuados para, en su nombre, ponerlas en práctica.

B) La oferta de asistencia sanitaria tiene una demostrada capacidad para generar su propia demanda de modo ilimitado, demanda reforzada tanto por la elevación de nuestro nivel de vida, como por el envejecimiento persistente de nuestra población, apoyada, en última instancia, por una pertinaz presión tecnológica hacia la utilización de nuevos y siempre más caros productos en nuestros hospitales.

C) La descoordinación que la proliferación de distintos niveles competenciales territorial y funcionalmente hablando (entidades locales, comunidades autónomas, estado, diputaciones) introducen en el sistema, no como mal necesario e inevitable, sino como escenario de un mayor acercamiento al ciudadano, requieren un importante esfuerzo de armonización y cooperación.

Por último,

D) Las necesidades cambiantes y diversas en materia de salud, propias de una sociedad en continua evolución, así como una prolífica actividad científica investigadora, que proporciona constantes innovaciones tecnológicas con inmediata repercusión sobre la salud de los ciudadanos, configuran un mercado sanitario absolutamente $d i$ námico y necesitado de importantes dosis de coherencia en cuanto a los criterios de asignación de los recursos públicos destinados a fines sanitarios.

La necesidad de conjugar los flujos de intereses mencionados, así como la gestión de los condicionantes detallados, procurando orientar los recursos sanitarios hacia la consecución de los objetivos propuestos, 
exige la existencia de unas organizaciones enormemente complejas, en las que la Función Directiva se hace no solo necesaria, sino imprescindible, integrando capacidades y concitando voluntades, para su máximo aprovechamiento dentro del marco jurídico-económico existente en cada momento.

Después de propuesta una posible definición de Función Directiva y establecida la necesidad de su existencia, en función de los factores que condicionan el marco en que hemos de prestar nuestros servicios sanitarios, habremos de profundizar en las características de la Función Directiva que decimos necesitar.

\section{¿Que función directiva se necesita?}

\section{En principio, intuimos cómo NO DEBE SER:}

- No debe de ser una F.D. trinchera, ante actuaciones o políticas no acordes con las demandas de la ciudadanía (trinchera externa), o bien ante las reclamaciones o exigencias de sus propios profesionales, respecto de los organismos competentes para su resolución(trinchera interna).

- No debe de ser una F.D. portavoz de los intereses de los profesionales, pues existen órganos e instancias de representación sobradamente acreditadas que, por otra parte, ejercen gran parte de su actividad precisamente ante las direcciones de las Instituciones.

- No debe de ser una F.D. frustrante de las expectativas generadas, a veces de modo inadecuado, desde otras instancias.

- No debe de ser una F.D. espectadora, dedicada a dar explicaciones de por qué suceden las cosas.

- No debe de ser una F.D. heróica, donde la asunción de problemas y conflictos no guarde la más mínima relación con la competencia para resolverlos.

- No debe de ser una F.D. parche, donde la competencia técnica y profesional se obvie por otras consideraciones coyunturales.

- No debe de ser una F.D. complaciente, con cuantas influencias exteriores e interiores se presenten y que puedan condicionar de modo determinante sus decisiones de gestión, tratando de evitar el «conflicto» a toda costa. 
Entonces, ¿COMO DEBERA SER?

LA FUNCION DIRECTIVA COMO FUNCIÓN INTEGRADORA DENTRO DE LA PROPIA ORGANIZACIÓN Y DE LA ORGANIZACIÓN DENTRO DEL SISTEMA.

La Organización se forma a partir de las personas que la componen, de los demás recursos (materiales e inmateriales) y las relaciones que se establecen entre ellos, para la obtención de los fines de la misma. En este contexto, la F.D. cumple un papel INTEGRADOR de los objetivos individuales, colectivos y organizativos, gestionando los recursos puestos a su disposición, para lo cual:

ORDENA/COORDINA recursos humanos y materiales, en un entorno plagado de CONDICIONANTES-RESTRICCIONES y con un determinado nivel de COMPETENCIAS, generalmente insuficientes, debiendo obtener unos resultados como si unos y otros no existieran. Es decir, debe de comportarse como si fuera poseedor de las cuatro cualidades necesarias para dirigir: CAPACIDAD, AUTORIDAD, PODER e INFLUENCIA.

En consecuencia:

1.- AJUSTARA EL GASTO/COSTE-PRESUPUESTO, entre ellos sus propias retribuciones.

2.- MOTIVARÁ, aunque no cuente con demasiados instrumentos para hacerlo.

3.- Se preocupará por los CLIENTES:

a) PROFESIONALES que perciben como retribución parte de los fondos presupuestarios y determinan la cantidad y destino final del gasto, como consecuencia de su actividad. En quien un directivo debe pensar antes de tomar una decisión.

b) CIUDADANOS destinatarios de los servicios, que sufragan con sus impuestos. En quien un directivo debe pensar durante toda la jornada laboral.

c) PODERES PUBLICOS que deciden las políticas y líneas estratégicas del servicio sanitario a prestar, administrando los impuestos de los ciudadanos. En quien un directivo debe pensar las $24 \mathrm{~h}$. del día.

Todo ello con criterios de CALIDAD.

Ello se traduce en una serie de actividades:

- Explicar y convencer de los LIMITES DEL GASTO a los PROFESIONALES que habrán de utilizarlos para la prestación de atención sanitaria. 
- Racionalizar y asignar EFICIENTEMENTE los recursos.

- Planificar la actividad sanitaria, con los niveles establecidos de CALIDAD Y CANTIDAD, CONTROLANDO adecuadamente su producción a través de los mecanismos determinados para ello.

Estas actividades requieren el desarrollo, entre otras, de las siguientes ESTRATEGIAS:

1. Planificación

2. Reorganización de recursos

3. Reestructuración de la organización

4. Implantación de herramientas de dirección (dpo, dirección de proyectos etc).

Para cuyo desarrollo es preciso:

- Contar con un plan de comunicación interna y externa, que garantice, a los diversos agentes que intervienen en la prestación del «Producto Hospitalario», el conocimiento de toda la información relevante, así como a la comunidad «usuaria», el conocimiento del «donde», «cuando» $\mathrm{y}$ «como» de dichas prestaciones.

- La implicación de todos los profesionales en la gestión de su propia actividad con los criterios establecidos en toda la organización: que cada empleado sea capaz de gestionar su puesto de trabajo orientado a los fines de la organización.

- Un Sistema de Información para la Gestión, preciso en su contenido, adecuado a las decisiones que se espera tener que tomar $\mathrm{y}$ generado con la periodicidad necesaria.

Finalmente, no me resisto a hacer un poco de corporativismo, tiene uno tan pocas ocasiones...

PARECE CLARO QUE LOS DIRECTIVOS DEBEN OCUPARSE DE TODO AQUELLO QUE TENGA INFLUENCIA EN LA ORGANIZACIÓN, PERO, ¿QUIEN SE OCUPA DE LOS DIRECTIVOS?

PORQUE, ¿QUIÉN EJECUTA LA FUNCION DIRECTIVA? ¿SON MAQUINAS? ¿NO?

ENTONCES, ¿LO HACEN PERSONAS? 


\section{EN ESE CASO, ¿TENDRAN LAS MISMAS NECESIDADES, EXPECTATIVAS, LIMITACIONES... QUE EL RESTO \\ DE LAS PERSONAS?}

Cuáles pueden ser estas aspiraciones:

- Acceder a los instrumentos de gestión que le permitan realizàr su actividad con garantías de éxito, asumiendo, en consecuencia, los riesgos derivados de unos resultados inadecuados.

- Reconocimiento del desempeño.

- Cierta expectativa temporal que permita planificaciones a medio plazo. Cierta estabilidad laboral, ligada al cumplimiento de objetivos (viables y proporcionales a los medios dispuestos). Cierta correlación entre la labor realizada y las retribuciones percibidas.

Estas cuestiones, que se entienden como perfectamente normales cuando se plantean respecto del resto de los colectivos que componen nuestras organizaciones, ¿Por qué suenan tan raras referidas a los directivos?

\section{Bibliografía}

1 De Manuel, E., Silió, F. Gestión Sanitaria en el Siglo XXI. Escuela Andaluza de Salud Pública. Granada. 1996.

2 OHMAE, K. The mind of the strategist. Mc. Garw Hill, Nueva York. 1982.

3 CHAMPY, J. Reengineering management: The mandate for new leadership. Harper Business. Nueva York. 1995. 